\title{
Cognitive function of Metaphor in Economy
}

\author{
Lu Hongyan \\ Xiamen University Tan Kah Kee College, Zhangzhou, China \\ +86-18159633915 \\ Luhongyan@xujc.com
}

Keywords: Abstract Concepts, Cognitive Function, Economic Language

\begin{abstract}
Metaphors are widely in the economic texts in order to help the common better understand the abstract terms in economy. Metaphors provide perfect facility for the realization of economic description and reasoning. The cognitive function of metaphor is mainly reflected on the three aspects: the fundamental base for the organization of human conceptual system; the indispensable tool for the organization of human experience; and offers a new perspective for us to know things. Based on analysis of economic texts, we focus on how metaphor, through the three functions, helps to realize the description and reasoning of the relatively highly abstract concepts in the economics language, to prove metaphor is indispensable for the economic language.
\end{abstract}

\section{Introduction}

Metaphor has been mainly taken as a matter of language for the past years, and thus the study of metaphor seldom went beyond its function as a rhetorical device. Cognitive linguistics takes metaphor as a way for us to conceptualize the world around us. Layoff and Johnson explain metaphor as the mapping from the source domain to the target domain in Metaphors We Live By and abstract concepts are largely metaphorical. According to them, metaphor is pervasive in everyday life, not just in language, but in, thought and action. (Lakoff \& Jonson: 1980:3). Here they clearly claimed that metaphor is not just a matter of words, but of the thought and action. Metaphor has rhetorical function, linguistic function, cognitive function and social function (Su Ding fang; 2000).

\section{The features of economic language}

Economics has been regarded as a subject of science, because it is mainly about the description of economic phenomena, the conclusion of the economic regulars, and prediction of economic developmental tendency through abstract observation and reasoning. So the concepts in the economics are rather abstracts. In his book "The Romantic Economist", on metaphors in economics, Richard Bronk writes:

"When economists use mathematical models to represent some aspect of social reality, they are writing or thinking in a metaphorical language; and the particular underlying structure and logic of this language permeates and constrains their vision, so that their reading of social reality may be quite different from those using other metaphors and other languages. This is often overlooked by economists who may assume that they are combining the timeless verities of mathematics with unbiased scientific observations of the facts 'out there' to get at some objective truth. While others may see through a glass darkly, economists often implicitly believe that they can see the world as it really is. One of the most profound lessons of Romanticism explored is that we can in fact never have unmediated access to reality. Even the observations and findings of the supposedly 'objective' sciences are structured by the particular languages, conceptual categorizations and metaphors used." The adoption of metaphor offers the operable facility for the economists' lingual realization, which makes their abstract reasoning possible. For example, the economists adopt the spatial metaphor to represent to state of the economy, such as, more is up; and less is down. It is not uncommon to see the sentence like: The Treasury’s 10 -year note rose 7/32, to 93 22/32. The yield fell to 3.39 percent, from 
3.41 percent late Wednesday. The developmental state of the economy is conceptualized through the spatial metaphor which makes it possible for us to visualize the change in its "quantity".

\section{The cognitive function of metaphor in economy}

Metaphor is dispensable in economic language for it is deeply rooted in our conceptual system. We cannot imagine how our conceptual world goes on without metaphor. The economic language without metaphor is almost impossible for the economists to undertake the realization of the economic description, and for the common to get access to the economy either. Every social individual is inevitably involved in economy, as far as he wants to own a normal life, so it is necessary to represent those highly abstract concepts in the economics in a way that is much more concrete for the common in their understanding. We tend to map the concepts of living creature into the economic concepts, and thus there is the conceptual metaphor "ECONOMY IS HUMAN BENING”. The growing stage of the human: birth - growth - maturity - death can be mapped in to the economy, like:

1) The primary reason is the infant-industry argument is difficult.

2) The buyer can hold the bond until maturity or can sell the bond...

The health state of a human being can be mapped into that of the economy. The economy that moves forward can be said healthy and while a problematic economy is ailing or sick.

America's economy will be weak in 2010, but policymakers should dispense the pain - killers with care.

More drugs do not always speed a patient's recovery. And strong medicine can have unpleasant side-effects. These medical homilies are worth bearing in mind as America's economy enters 2008. With a year of weak growth in prospect and a high risk of recession, the clamor of action is getting louder.

Microsoft's entertainment and devices division, which includes Kinect and Xbox, grew by 55 percent, to about $\$ 3.7$ billion.

The economist Brian Arthur has used playing chess as an analogy for the computational implausibility of an economic agent ever working out the optimal move in the complex game of real markets. Such similes and analogies can often profoundly influence the way we think about and model aspects of economic behavior. The effect on the way we view the world becomes more all-pervasive, however, when a metaphor comes to constitute the very conceptual structure with which we look at and analyze social reality.

\subsection{Metaphor is the fundamental base for the organization of human conceptual system.}

A great many of concepts in our conceptual system is realized through metaphor. That is because metaphor is one of the most basic ways for the organization of human conceptual system. Primary metaphors lie deeply in our conceptual system and they play the role of the core concepts. According to Lakoff, we acquire a large system of primary metaphors automatically and unconsciously simply by functioning in the most ordinary ways in the world from our earliest years. The importance of metaphor in our daily way of thinking and linguistic expression can never be underestimated, in other words, without metaphor, there is no human language, and thus no human conceptual system at all.

The whole conceptual system of economy is mapped from other conceptual domain through metaphor. Taking the orientation metaphors: "MORE IS UP”, “GOOD IS UP”, "LESS IS DOWN”, and "BAD IS DOWN" in economy for example: E.g. 1) Shares declined slightly in after-hours trading. The decline of the share is means the state of "down", as the level in a container falls down, the content in it becomes less. So the shares "declined" means the quantity of the share becomes less. Since metaphor is the fundamental base for the organization of human conceptual system, not to mention the role it plays in the organization for our conceptual system in the economy. 


\subsection{Metaphor is the indispensable tool for the organization of human experience.}

We conceptualize the experience of one domain from the other through metaphor, which makes it possible for us to organize and experience one that is relatively unfamiliar and thus we can form our own views and take the corresponding action. The conceptual system of human is based on “ontological metaphor”, which includes entity and substance metaphor, container metaphor and so on. Entity and substance metaphor enables us to take part of experience as entity or substance of the same sort. Once regarded as entity or substance, the relatively abstract and subjective experience can be categorized and quantified, and thus can be rationally analyzed. In economy, most of concepts are dealt with by treating them as "entity or substance", because the entity and substance metaphor makes it possible for us to inference the experience in economy. Taking inflation in economy for example, the economic phenomenon -inflation is regarded as kind of "entity", such as:

INFLATION IS ENTITY

Inflation in lowering our standard of living

If there is much more inflation, we'll never survive.

We need to combat inflation.

Inflation is treated as an entity- enemy, which provides us the experience we are familiar with, and thus we can refer to and quantify inflation, and thus recognize its feature of a certain aspect, which, in return, is the reason for us to take the corresponding action. Ontological metaphor like that is indispensable in economy, without which, we can never realize the description, inference, inclusion, prediction, and judgment of the economic activity.

Besides entity and substance metaphor, container metaphor is another main ontological metaphor. That is because human beings are, in fact, entities independent from the world around us. Each individual is a container with boundary, dividing the container into two sides: the inside and outside. The container metaphor is widely used in our daily life, which is the same with the economic field. In economic text, the conceptual metaphor "MARKET IS CONTAINER" is not unfamiliar to us, like:

The new products will enter the market within three months.

The demand for this product in the market has already reached saturation.

Many of their new series products will come into the market.

\subsection{Metaphor offers a new perspective for us to know things.}

Metaphor is the conceptual process by using the experience in one domain to discuss about the experience in another. According to Lakoff ( Lakoff 1980: 10): The very systematicity that allows us to comprehend one aspect of a concept in terms of another will necessarily hide other aspect of the concept. In allowing us to focus on one aspect of a concept, a metaphorical concept can keep us from focusing on other aspects of the concept that are inconsistent with other metaphor.

The highlighting of one aspect by metaphor can give rise to a new context which can be regarded as a new perspective and thus people can know about something new in reality. In economy, a great many of metaphors are used for us to understand the economic phenomena, which, to some degree, affects our economic policies. The metaphor -- "invisible hand", used by Adam Smith-the father of economy in his 1776 book An Inquiry into the Nature and Causes of the Wealth of Nations, to conceptualize the power that govern the market regulars in economy, was claimed as the classic of modern economics. The abstract description in economy of "invisible hand" is: in a free market, both the producers and the consumers can automatically accommodate the allocation of the recourse such as labor, time, and goods and materials according to the market regulars, instead of the overmuch governmental intervention, so as to reach optimization of the social resource. When we conceptualize this abstract economic phenomenon through the "invisible hand", we can also get some new extended perspectives of it, like: when the government prevents prices from adjusting naturally to supply and demand, it impedes the invisible hand's ability to coordinate the millions of households and firms that make up the economy... These planners lacked the information that gets reflected in prices when prices are free to respond to market force. Central planners failed because they tried to run the economy with the one hand tied behind their backs - the invisible hand of the market. 
The source domain: the invisible hand may not work if it is tied tightly, maps into a target domain: the market regulars may dysfunction if the government enforces some effects by disregarding the price. What is highlighted is that the ignorance of the tool means the constraint of the function of the hand. The concept is the ignorance of price will finally lead to the dysfunction of market regulars. Under such circumstances, the government plays the role of central planner.

\section{Conclusions}

The study on metaphor has already turned from just regarding it as a rhetorical device to its function as the way we conceptualize the world around us. Since the abstract concepts are largely metaphorical and the concepts in economy are highly abstract, metaphors are enormously employed in economy. After explaining the working mechanism of metaphor as the way of cognition, we discuss the cognitive functions of metaphor from three aspects by analyzing the examples in economy. In conclusion, metaphor not only enables us to realize the description of the abstract concepts and to experience the experience in economy but also provides us new perspectives which greatly influence our views towards the concepts in economy.

\section{References}

[1] George Lakoff and Mark Johnson, Metaphor We Live By, Chicago. The University of Chicago Press, 1980

[2] Di Yanhua,Yangzhong. A Cognitive Analysis of Conceptual Metaphors in Economic Crisis Reports [J].Journal of Northeast Normal University, 2010（5）

[3] Kong Mingde. A Cognitive Approach to Conceptual Metaphors in Economic Discourse [J]. Foreign Language and Foreign Language Teaching Research,2002,(2)

[4] Su Dingfang. On the Understanding Process and Characteristics of Metaphor[J]. Foreign language and Foreign Language Teaching Research.2000a (4)

[5] Su Dingfang. On the Cognition of Metaphor and Its Linguistic Reasons[J]. Foreign Languages Research. 2000b(2)

[6] Su Dingfang. Studies in Metaphor [M].Shanghai: Shanghai Foreign Language Education Press, 2000:10

[7] Su Dingfang. On the Cognitive Function of Metaphor[J]. Foreign Language Research,2001 (2).

[8] Wang Yahui. Conceptual Construal of Structural Metaphors in Economic Discourse [J].Journal of Fuzhou University,2010(3).

[9] Yang Youwen,Yang Xuecai. A Study of Metaphor in Economic English [J]. Journal of Shandong Institute of Education,2008（2） 